\title{
Choosing Under the Influence: A Drug-Specific Mechanism by Which the Setting Controls Drug Choices in Rats
}

\author{
Youna Vandaele ${ }^{1,2,5}$, Lauriane Cantin ${ }^{3,5}$, Fuschia Serre ${ }^{4}$, Caroline Vouillac-Mendoza ${ }^{1,2}$ and Serge H Ahmed ${ }^{*, 1,2}$ \\ 'Université de Bordeaux, Institut des Maladies Neurodégénératives, UMR CNRS 5293, Bordeaux, France; '2Institut des Maladies \\ Neurodégénératives, UMR CNRS 5293, Bordeaux, France; ${ }^{3}$ Institut Bergonié, Bordeaux, France; ${ }^{4}$ SANPSY, CNRS USR 34I3, Université de \\ Bordeaux, Bordeaux, France
}

\begin{abstract}
Ample evidence shows that the setting can control drug choices in both humans and animals. Here we reveal in rats that a major mechanism of this control involves a regulation of the drug influence on other competing options at the time of choice. Briefly, rats were offered a choice between a drug dose (cocaine or heroin) and a brief access to water sweetened with saccharin in two different settings. In one setting, choosing under the influence was not possible and rats largely preferred saccharin over either cocaine or heroin. In contrast, when the same rats were shifted to a setting where choosing under the influence was possible, they chose the drug either nonexclusively or exclusively depending on whether the drug enhanced or suppressed sweet reward, respectively. Thus, when rats were under the orexigenic influence of heroin at the time of choice, they more frequently chose saccharin in alternation with heroin. In contrast, when rats were under the anorexic influence of cocaine, they stopped choosing saccharin and continued taking cocaine exclusively. These settingand drug-specific changes in preference were rapid and reversible, and could be induced by passively administering cocaine or heroin before choice. Finally, rats behaved as if they were oblivious to the drug influence on their choices. This behavior could explain why rats are vulnerable to harm themselves, sometimes to the point of death, in settings where choices are made under the drug influence, notably if this influence excludes other important options or, conversely, enhances harmful ones.

Neuropsychopharmacology (2016) 4I, 646-657; doi: I 0.1038/npp.20 I5.195; published online 22 July 2015
\end{abstract}

\section{INTRODUCTION}

Mainstream experimental research on drug addiction involves nonhuman animals-most frequently rats-that are provided with ready access to drugs for intravenous selfadministration but without access to other rewarding options (Ahmed, 2012). There is growing awareness that such lack of options may limit the validity of this research for understanding drug addiction as a drug use disorder (Ahmed, 2005, 2010; Ahmed et al, 2013; Alexander and Hadaway, 1982; Cantin et al, 2010; Caprioli et al, 2015b; Carroll et al, 1989; Kerstetter et al, 2012; Le Sage, 2009; Lenoir et al, 2007, 2013; Liu and Grigson, 2005; Perry et al, 2013; Thomsen et al, 2013; Tunstall and Kearns, 2013; Zernig et al, 2013). Indeed, when there is no valuable alternative to the drug, drug self-administration may merely reflect a normal reaction to the lack of choice as opposed to reflecting a disordered behavior caused by an underlying dysfunction (Ahmed, 2010; Ahmed et al, 2013; Hyman and Malenka, 2001). As it turns out, providing rats with an alternative nondrug reward, generally a sweet food or

*Correspondence: Dr SH Ahmed, Université de Bordeaux, Institut des Maladies Neurodégénératives, UMR CNRS 5293, I 46 rue Léo Saignât, Bordeaux 33076, France, Tel: +33 557 57I 566, Fax: +33 556900 278, E-mail: serge.ahmed@u-bordeaux.fr

${ }^{5}$ The first two authors contributed equally to this work.

Received I April 2015; revised 22 June 2015; accepted 24 June 2015; accepted article preview online I July 2015 drink, during drug access has produced dramatic but contrasting results. This is particularly striking in studies involving a choice between cocaine and sweet reward. In most of these studies, virtually all rats rapidly and almost completely stopped drug use in favor of the competing option (Cantin et al, 2010; Carroll and Lac, 1993; Carroll et al, 1989; Kerstetter et al, 2012; Le Sage, 2009; Lenoir et al, 2007, 2013; Madsen and Ahmed, 2015; Perry et al, 2013; Tunstall and Kearns, 2013; Tunstall et al, 2014). Suppression of cocaine use in favor of sweet reward developed even after extended access to cocaine self-administration and could not be surmounted by maximally increasing the dose of cocaine (eg, up to $1.5 \mathrm{mg}$ per injection) (Cantin et al, 2010; Lenoir et al, 2007). Remarkably, a complete and long-term suppression of methamphetamine seeking by food choice was also demonstrated in rats after different histories of extended access to methamphetamine self-administration that are known to induce addiction-like behavior (Caprioli et al, 2015a, b). In contrast, in other choice studies, rats eventually shifted their choice from sweet reward to cocaine when the dose of cocaine was sufficiently high (ie, up to $0.5 \mathrm{mg}$ per injection) (Thomsen et al, 2008, 2013).

The origin of this discrepancy has not been elucidated yet. It is clearly not attributable to a difference in the higher dose of cocaine or the type of nondrug reward used between choice studies (see above). Here we suggest that the main difference lies in how the choice setting (ie, the way choice trials are presented and structured) controls the drug influence at the time of choice. In studies employing a 
setting where choosing under the drug influence was not possible (eg, by imposing a sufficiently long interchoice interval for drug dissipation before the next choice), most rats preferred sweet reward over cocaine, even at the high doses (Lenoir et al, 2007). In contrast, in studies using a setting where choosing under the drug influence was possible (eg, by not imposing a minimum interchoice interval), virtually all rats preferred the high doses of cocaine (Thomsen et al, 2008, 2013). Thus, it seems that rats choose cocaine when they are under the drug influence at the time of choice and otherwise choose the nondrug reward. This hypothesis is supported by a recent choice study that uniquely manipulated the duration of the interchoice interval while keeping all else equal. As expected, when the interchoice interval was sufficiently shortened to allow the drug influence at the time of choice, most rats shifted from sweet reward to cocaine almost exclusively (Kerstetter et al, 2012).

This hypothesis is also consistent with many previous studies showing the importance of the setting in controlling drug choices in both humans and animals (Alexander and Hadaway, 1982; Badiani, 2013; Falk, 1983; Faupel, 1987; Zinberg, 1984), and reveals that a possible major mechanism of this control would involve a regulation of the drug influence at the time of choice. One can envision at least three different, though not necessarily mutually exclusive, explanations for the direct influence of cocaine on choice outcomes. First, cocaine may directly interfere with choicemaking processes, such as, for instance, deliberation, decision, and action selection (Setlow et al, 2009; Spronk et al, 2013). However, it is difficult to see how this general influence should preferentially promote the choice of cocaine over the nondrug option and not the other way around. Second, cocaine may directly increase the value of or motivation for cocaine at the time of choice, through a direct motivational priming effect, not unlike that measured in drug reinstatement experiments (Ahmed and Cador, 2006; de Wit and Stewart, 1981; Shaham et al, 2003), and thus bias choices toward the drug. Third, cocaine may also directly suppress responding for sweet reward at the time of choice, for instance, by decreasing the incentive value of associated cues and/or responses, and thereby bias choice toward cocaine. This direct negative influence on sweet reward could be mediated by the well-known anorexic effects of cocaine (Balopole et al, 1979; Cooper and van der Hoek, 1993; Wolgin and Hertz, 1995; Woolverton et al, 1978).

The goal of the present series of experiments was to measure the specific contribution of the latter two mechanisms. As no current intervention exists that can selectively carve the anorectic effects of cocaine out of its other behavioral effects, we chose to address this question by comparing and contrasting cocaine with heroin. Heroin, like cocaine, can effectively reinstate drug seeking (de Wit and Stewart, 1983; Lenoir and Ahmed, 2007; Shaham et al, 2003) but, unlike cocaine, has orexigenic rather than anorexic effects on sweet reward (Cooper, 1982; Parker et al, 1992; Rideout and Parker, 1996). Thus, by manipulating the influence of these two drugs at the time of choice, through specific shifts in choice settings, we should be able to determine which mechanism (common modulation of drug motivation versus opposite modulation of motivation for sweet reward) primarily influences choice behavior. Briefly, if the primary mechanism is a direct modulation of drug motivation, then a shift to a setting where choosing under the influence is possible should shift choice to the drug available, be it cocaine or heroin. In contrast, if the primary mechanism is a direct modulation of the nondrug option, then the same shift in choice setting should shift choice to or away from the drug depending on whether the drug available is cocaine or heroin, respectively.

\section{MATERIALS AND METHODS}

\section{General Behavioral Procedures}

Initial operant training. Before any choice testing, young adult, male Wistar rats $(n=115$, weighing on average between 344 and $446 \mathrm{~g}$ at the beginning of the choice experiments) were first trained for 3-5 weeks under a fixedratio (FR1 or 2$)$ schedule of sweet water $(0.2 \%$ saccharin or $20 \%$ sucrose) and intravenous cocaine $(0.25 \mathrm{mg}$ per injection) or heroin $(0.01 \mathrm{mg})$ self-administration on alternating daily sessions, six sessions a week (see Supplementary Methods).

Discrete choice procedure. Each daily choice session consisted of 12 discrete trials spaced $10 \mathrm{~min}$ apart and divided into two successive phases: reward sampling (4 trials) and choice (8 trials). During the reward sampling phase, each trial commenced with the presentation of one lever at a time in the following order: drug lever-sweet lever-drug lever-sweet lever. If rats responded within $5 \mathrm{~min}$ on the available lever, their behavior was rewarded with the corresponding reward (ie, intravenous delivery of drug or $20 \mathrm{~s}$ access to sweet water). Reward delivery was signaled by retraction of the lever and illumination of the cue light above the lever. If rats failed to respond within $5 \mathrm{~min}$, the lever was retracted and no cue light or reward was delivered. During the choice phase, each trial commenced with the simultaneous presentation of the sweet lever and the drug lever. Rats were able to respond to either of these two levers to self-administer the corresponding reward. Reward delivery was signaled by retraction of both levers and illumination of the cue light above the selected lever. Thus, for the duration of each single trial, choice of one reward excluded the other. If rats failed to respond to either lever within $5 \mathrm{~min}$, both levers were retracted and no reward was delivered. The operant response requirement was set to two consecutive responses to avoid accidental choice.

Importantly, a 10-min intertrial interval was used here, as well as in all previous experiments from this laboratory, because it takes $\sim 10 \mathrm{~min}$ for the locomotor effects of the testing dose of cocaine $(0.25 \mathrm{mg})$ or heroin $(0.01 \mathrm{mg})$ to dissipate (Cantin et al, 2010; Lenoir et al, 2007, 2013). As a result, this procedure defines a setting where choosing under the drug influence is not possible or only minimal, even if rats happen to choose cocaine on most trials.

Continuous choice procedure. Unlike the discrete choice procedure, there was no enforced interchoice interval in the continuous choice procedure. Both the sweet and drug levers were presented simultaneously and remained continuously available throughout the duration of the session. Completion of the response requirement on either lever resulted in the 

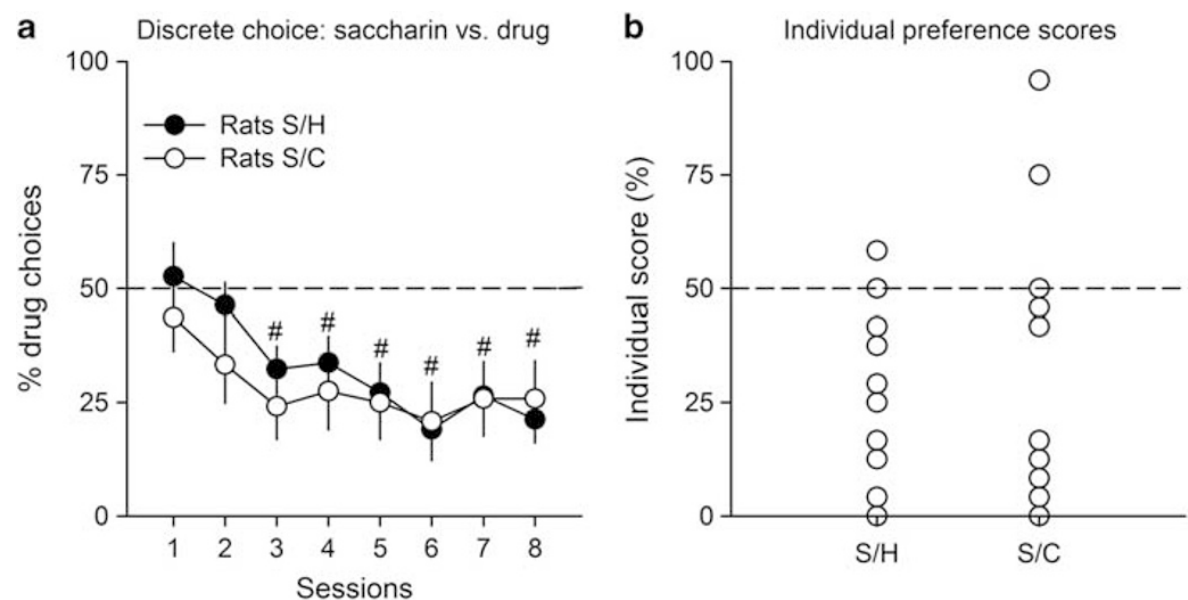

Figure I Choice between saccharin and heroin or cocaine in the discrete choice setting. (a) Mean percent heroin $($ rats $\mathrm{S} / \mathrm{H}, n=17)$ or cocaine (rats $\mathrm{S} / \mathrm{C}$, $n=16$ ) choices $( \pm$ SEM) as a function of testing sessions. The horizontal dashed line at $50 \%$ represents the indifference level. The doses of heroin and cocaine per injection were 0.01 and $0.25 \mathrm{mg}$, respectively. Water was sweetened with $0.2 \%$ of saccharin. "Different from the indifference level ( $p<0.05, t$-test). (b) Distribution of individual preference scores in rats $S / H(n=17)$ and rats $S / C(n=16)$. Individual preference scores were computed by averaging percent of drug choices over the last three choice sessions.

delivery of the corresponding reward (ie, intravenous drug delivery or $20 \mathrm{~s}$ access to sweet water) and was signaled by illumination of the cue light above the selected lever. Thus, in this continuous choice procedure, rats have continuous access to both options for the entire duration of the session. As a result and unlike the discrete choice procedure, this procedure defines a setting where choosing under the drug influence is possible once a drug choice is made.

\section{Specific Behavioral Experiments}

Experiment 1: Effects of a shift in choice setting on cocaine and heroin choices. This experiment sought to determine how choice between saccharin and drug self-administration is controlled by the setting. This was done by testing the same individual rats, first, under the discrete choice procedure and, then, under the continuous choice procedure. Two separate groups of FR2-trained rats were tested. One group, called rats S/C $(n=16)$, was initially trained to selfadminister $0.2 \%$ saccharin and $0.25 \mathrm{mg}$ cocaine on alternate daily sessions, whereas the other group, called rats $\mathrm{S} / \mathrm{H}$ $(n=17)$, was trained to self-administer $0.2 \%$ saccharin and $0.01 \mathrm{mg}$ heroin. After stabilization of saccharin and drug selfadministration (Supplementary Figure S1), rats S/C and rats $\mathrm{S} / \mathrm{H}$ were allowed to choose between the two under the discrete choice procedure until stabilization of drug choices (ie, no decreasing or increasing trend over three consecutive sessions). Next, the same rats were tested under the continuous choice procedure during one $2 \mathrm{~h}$ session. During the continuous choice session, rats had continuous access to both $0.2 \%$ saccharin and $0.25 \mathrm{mg}$ cocaine (rats S/C) or $0.01 \mathrm{mg}$ heroin $($ rats $\mathrm{S} / \mathrm{H})$. Finally, a third control group of rats, called rats $S / 0(n=14)$, was added to control for the effects of continuous access to drug self-administration on saccharin self-administration. They were trained to selfadminister only $0.2 \%$ saccharin during initial operant training. During testing, they were given exclusive and continuous access to saccharin for $2 \mathrm{~h}$.
Experiments 2-8. To better interpret the results from experiment 1,7 additional experiments were conducted using parametric variants of the general procedures described above. To avoid repetition and ease reading, the principle of each of these experiments is outlined in relevant places in the Results section. A complete description of these experiments is provided in Supplementary Information.

\section{RESULTS}

\section{Experiment 1: Effects of a Shift in Choice Setting on Cocaine and Heroin Choices}

When tested under the discrete choice procedure, both rats $\mathrm{S} / \mathrm{C}$ and rats $\mathrm{S} / \mathrm{H}$ rapidly developed a strong preference for saccharin over the drug available for choice (Figure 1a) $\left(\mathrm{F}_{(7,210)}=9.69, p<0.01\right)$. Analysis of individual preference scores over the last 3 sessions of choice reveals that regardless of the drug available during choice trials, the large majority of rats preferred to self-administer saccharin than cocaine $(81.2 \%$ or 13 out of 16 rats $\mathrm{S} / \mathrm{C})$ or heroin $(88.2 \%$ or 15 out of 17 rats $\mathrm{S} / \mathrm{H}$ ). The other rats preferred the available drug ( 2 rats $\mathrm{S} / \mathrm{C}$ and 1 rat $\mathrm{S} / \mathrm{H}$ ) or were indifferent $(1 \mathrm{rat} \mathrm{S} / \mathrm{C}$ and 1 rat $\mathrm{S} / \mathrm{H}$ ) (Figure $1 \mathrm{~b}$ ).

As predicted, when rats $\mathrm{S} / \mathrm{C}$ and rats $\mathrm{S} / \mathrm{H}$ were shifted to the continuous choice procedure, they developed two clearcut patterns of drug choices as a function of the drug available (Figure 2). When heroin was available, most rats S/H (ie, 65\%) first began self-administering saccharin before turning to heroin. Then, and regardless of their first choice, all rats without exception alternated between the two options until the end of the $2 \mathrm{~h}$ session (Figure 2a). The resulting distribution of heroin self-administration was similar to that measured during the first $2 \mathrm{~h}$ of the last FR training session of heroin self-administration (ie, during which rats $\mathrm{S} / \mathrm{H}$ had no choice than heroin) (Figure 2b). Similarly, the resulting distribution of saccharin self-administration was similar to that measured in control rats $\mathrm{S} / 0$ that had only access to saccharin for $2 \mathrm{~h}$ during testing (Figure 2e). These observations 


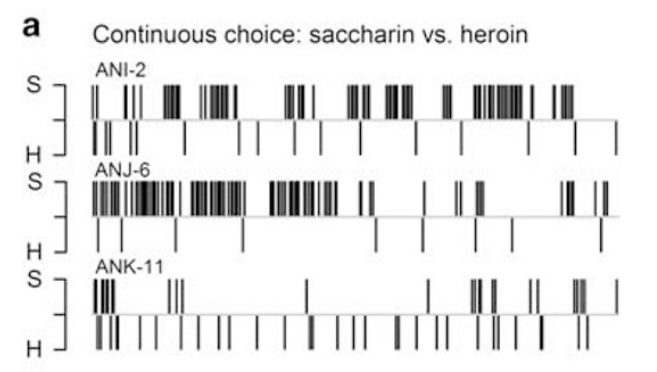

b No-choice condition: heroin
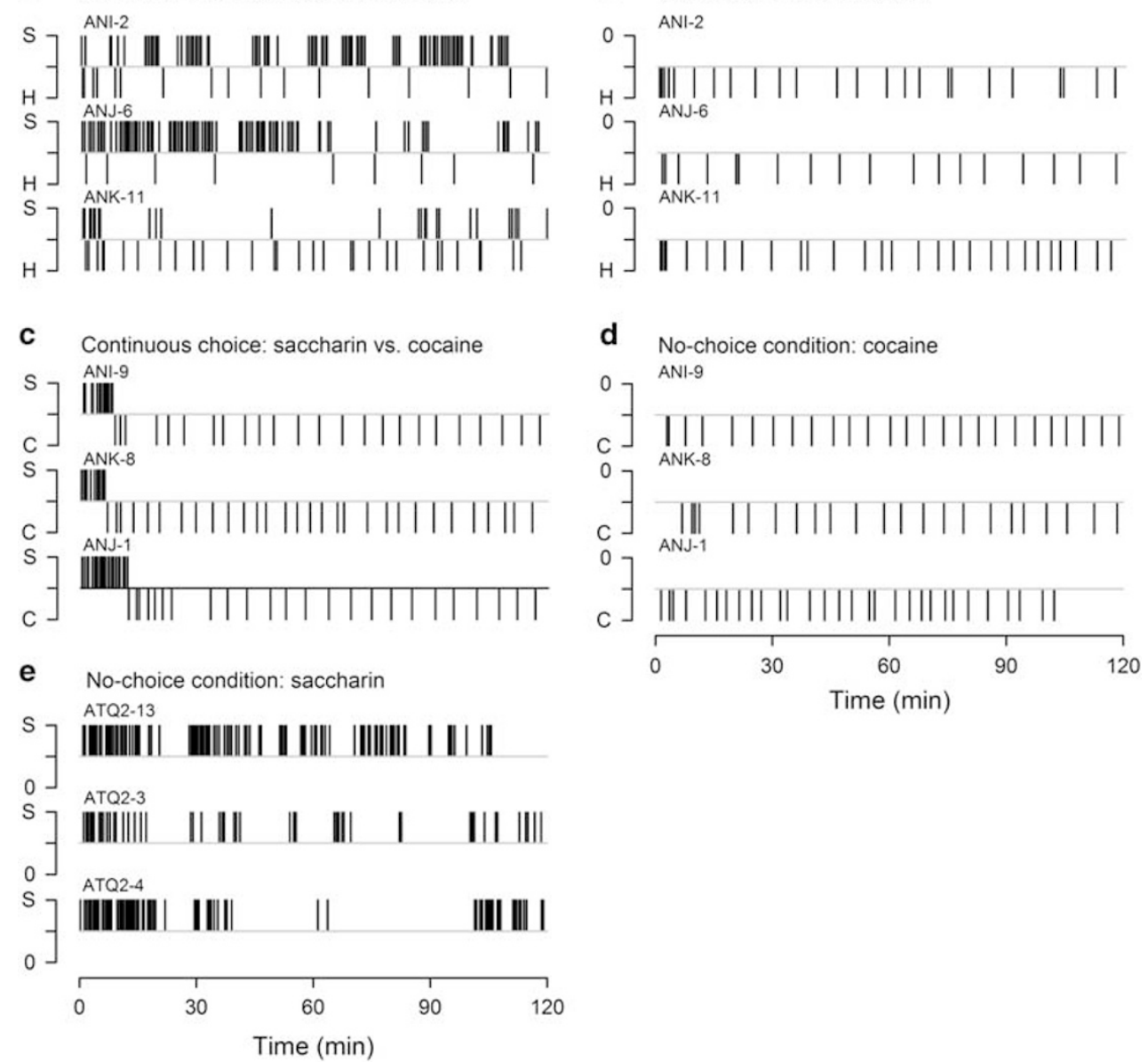

Figure 2 Choice between saccharin and heroin or cocaine in the continuous choice setting: representative individuals. Each graph represents a single session. Each vertical bar above or below the gray horizontal line corresponds to the delivery of a sweet or drug reward, respectively. Each alphanumeric code above each distribution corresponds to an individual rat. (a) Within-session distribution of saccharin (0.2\%) and heroin (0.0 I mg per injection) rewards during the first session of continuous choice in three representative rats $\mathrm{S} / \mathrm{H}$. (b) Within-session distribution of heroin rewards during the last FR training session in the same individual rats as in (a). (c) Within-session distribution of saccharin and cocaine (0.25 mg per injection) rewards during the first session of continuous choice in three representative rats S/C. (d) Within-session distribution of cocaine rewards during the last FR training session in the same individual rats as in (c). (e) Within-session distribution of saccharin rewards in three representative rats S/O.

show that heroin and saccharin are self-administered in parallel and do not seem to interfere with each other. In contrast, when cocaine was available for choice, a different pattern of behavior was observed (Figure $2 \mathrm{c}$ ). Like rats $\mathrm{S} / \mathrm{H}$, virtually all rats $\mathrm{S} / \mathrm{C}$ (87.5\%) first began self-administering saccharin before switching to cocaine, except for the 2 cocaine-preferring rats that began with cocaine. Then, and regardless of their first choice, all rats without exception continued to self-administer cocaine nearly exclusively (Figure 2c) and similarly to the last FR training session of cocaine self-administration (Figure 2d), as if they had no access to saccharin. In contrast, saccharin self-administration was suppressed compared with rats S/0 (Figure 2e). All the qualitative observations in rats $\mathrm{S} / \mathrm{H}$ and rats $\mathrm{S} / \mathrm{C}$ were confirmed by a quantitative analysis of the data obtained in all rats (Supplementary Figure S2 and Supplementary Results).

\section{Experiment 2: Effects of Passive Cocaine Administration on Responding for Saccharin}

To confirm that the pattern of exclusive cocaine selfadministration seen in a continuous choice setting is due to the direct acute effects of cocaine as opposed to a behavioral competition or conflict between operant responding for cocaine and operant responding for saccharin, a separate group of rats $(n=11)$ was passively administered with saline or cocaine during access to saccharin selfadministration. Passive injections were distributed according to a temporal pattern that roughly mimicked that of cocaine self-administration, with the first 3 injections $(0.25 \mathrm{mg})$ administered every $30 \mathrm{~s}$ to mimic initial drug loading followed by an injection every $4.3 \mathrm{~min}$ (Figure 3a). Saccharin self-administration during passive administration of cocaine was systematically lower than that during saline administration (Wilcoxon's test, $p$-values $<0.01$ ) and was not different from 0 ( $t$-test, $p$-values $>0.1)$ (Figure $3 b)$.

\section{Experiment 3: Effects of Food Restriction and Access to Sucrose on Cocaine Choices in a Continuous Choice Setting}

To assess the robustness of the results obtained in rats S/C in a continuous choice setting, a separate group of hungry rats 
a

Passive i.v. cocaine administration
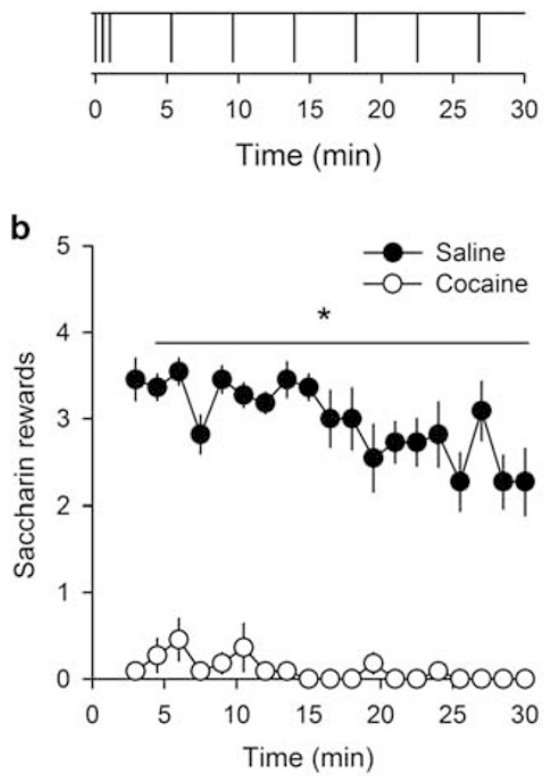

C Continuous choice: sucrose vs. cocaine in hungry rats
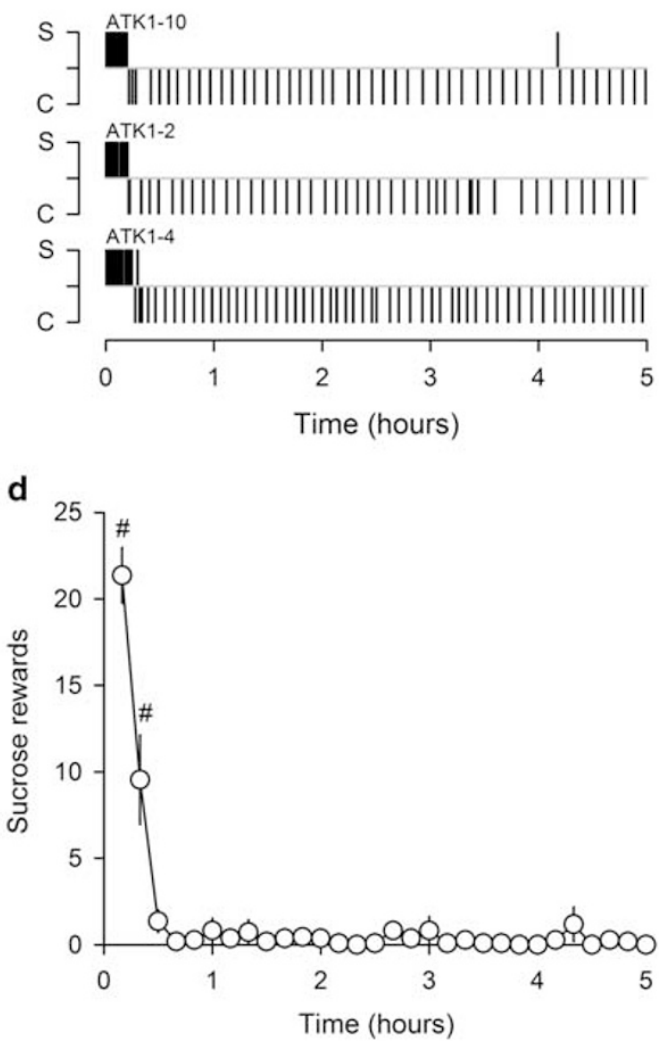

Figure 3 Cocaine-induced suppression of responding for saccharin. (a) Temporal distribution of programmed, passive saline or cocaine (0.25 mg) administration. Each vertical bar represents a programmed injection. (b) Mean ( \pm SEM) sweet rewards ( $0.2 \%$ of saccharin) during passive saline and cocaine administration. Lever $\mathrm{C}$ remains retracted throughout the 30 -min session. *Different from cocaine $(p<0.0$ I, Wilcoxon test). (c) Within-session distribution of sweet ( $20 \%$ of sucrose) and cocaine $(0.25 \mathrm{mg}$ ) rewards during a 5 -h session of continuous choice in 3 representative food-restricted rats (ie, $80 \%$ of their freefeeding body weight adjusted for growth). Each alphanumeric code above each distribution corresponds to an individual rat (see legend of Figure 2 for other details). (d) Mean ( \pm SEM) within-session time course of sucrose rewards during continuous access to cocaine for self-administration in food-restricted rats $(n=\mid 1)$. "\#ifferent from 0 ( $p<0.05, t$-test $)$.

$(n=11)$ was given continuous access to $20 \%$ sucrose and $0.25 \mathrm{mg}$ of cocaine during $5 \mathrm{~h}$. As rats $\mathrm{S} / \mathrm{C}$ from experiment 1 , most rats $(90.9 \%)$ first began to self-administer sucrose before switching to cocaine self-administration nearly exclusively until the end of the session (Figure 3c). A quantitative analysis of the data obtained in all rats revealed that sucrose intake was durably suppressed to 0 within $30 \mathrm{~min}$ (Figure 3d).

\section{Experiment 4: Effects of the Interchoice Interval on Cocaine Choices in a Discrete Choice Setting}

This experiment tested whether shortening the interchoice interval in a discrete choice setting is sufficient to induce a within-session shift to exclusive cocaine self-administration as seen in a continuous choice setting. To this end, a new group of rats $(n=24)$ was tested with a 1 - and 10-min interchoice interval in two 30-trial choice sessions. Because we predicted that lowering the interval from 10 to $1 \mathrm{~min}$ will shift choice to cocaine, the following analysis is restricted to the majority of rats $(n=18)$ that preferred saccharin at the 10 min interval (ie, percent of cocaine choices over the last 15 trials of the session $<50 \%)$. Not surprisingly, rats $(n=6)$ that preferred cocaine at the $10 \mathrm{~min}$ interval continued to prefer it at the $1 \mathrm{~min}$ interval (data not shown). In contrast, rats that preferred saccharin at the $10 \mathrm{~min}$ interval (Figure 4a) changed their behavior at the $1 \mathrm{~min}$ interval to exhibit a pattern of choices almost identical to that measured in rats $S / C$ in the continuous choice setting (Figure $4 \mathrm{~b}$ ). These qualitative findings were confirmed by an analysis of the evolution of percent of cocaine choices within the session using a sliding window of 8 choice trials (Interval: $\mathrm{F}_{(1,17)}=56.65, \quad p<0.01$; Interval $\times$ Window interaction: $\mathrm{F}_{(22,374)}=7.66, p<0.01$ ) (Figure $4 \mathrm{c}$ ).

\section{Experiment 5: Effects of the Dose of Heroin on Heroin Choices in a Continuous Choice Setting}

We next tested whether a much higher dose of heroin could eventually suppress saccharin self-administration in a continuous choice setting, like cocaine self-administration did. A separate group of rats $(n=7)$ was given a continuous choice between $0.2 \%$ saccharin and $0.08 \mathrm{mg}$ heroin for selfadministration over a long session (ie, $10 \mathrm{~h}$ to allow rats to self-administer a sufficient number of high heroin doses). This dose of heroin is 8 times higher than the dose tested in rats $\mathrm{S} / \mathrm{H}$ from experiment 1 . For comparison, the same rats were also subsequently tested on two separate $10 \mathrm{~h}$ sessions 
Discrete choice: saccharin vs. cocaine

a

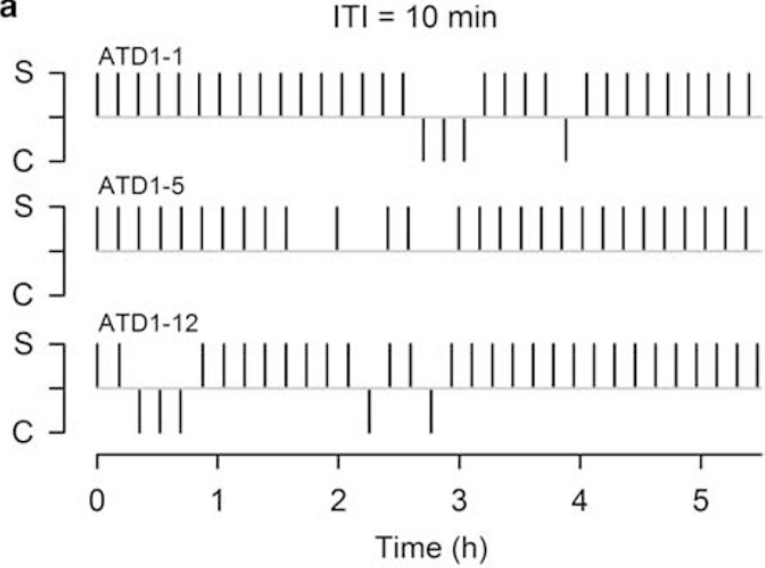

b $\quad I T I=1 \mathrm{~min}$
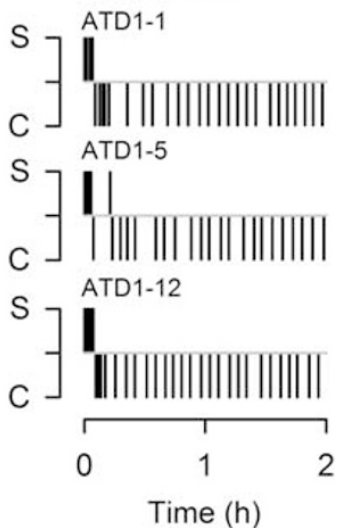

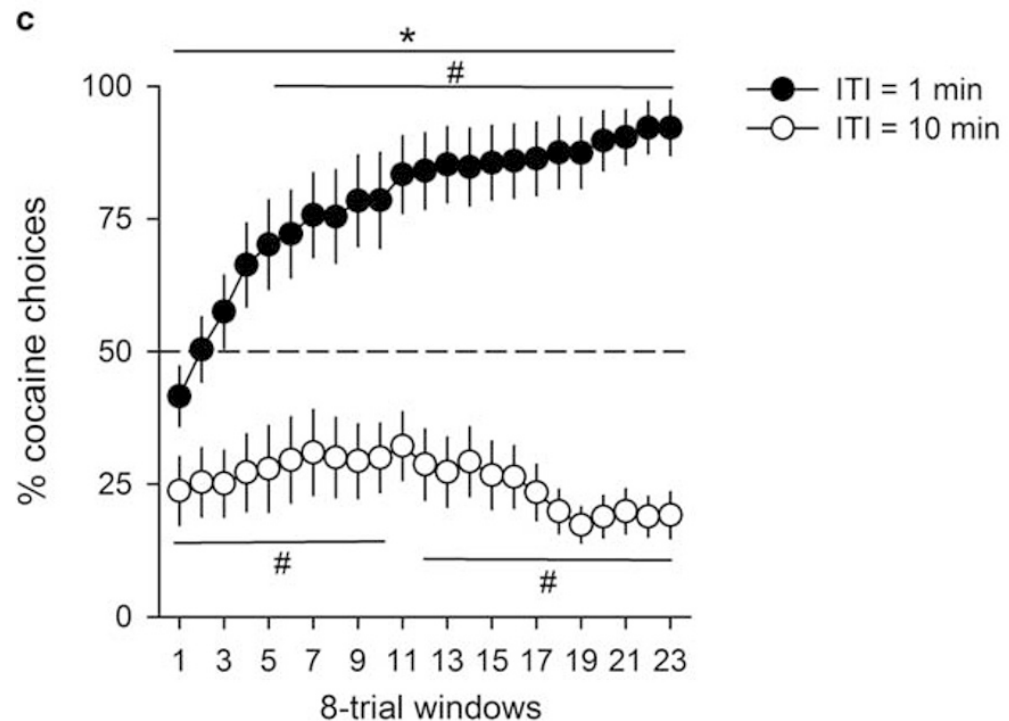

Figure 4 Effects of the interchoice interval on choice outcomes in a discrete choice setting. Within-session distribution of saccharin (0.2\%) and cocaine $(0.25 \mathrm{mg})$ choices with an intertrial interval (ITI) of $10 \mathrm{~min}(\mathrm{a})$ or I $\mathrm{min}(\mathrm{b})$ in the same 3 representative rats. Each alphanumeric code above each distribution corresponds to an individual rat. (c) Mean $( \pm$ SEM) percent cocaine choices within a session as a function of the interchoice interval $(n=18)$. The withinsession evolution of cocaine choices was computed for each individual rat using a sliding window of 8 consecutive choice trials (trials I to 8 ; trials 2 to 9 ; trials 3 to I0; and so on until trials 23 to 30$)$. *Different from the 10 min intertrial interval ( $p<0.01$, main effect, ANOVA with repeated measures); ${ }^{\#}$ different from the indifference level of $50 \%(p<0.05, t$-test).

with exclusive access to either $0.08 \mathrm{mg}$ of heroin or saccharin for self-administration. Overall, increasing the dose of heroin did not induce a pattern of exclusive heroin choices at the expense of saccharin (Figure $5 \mathrm{a}$ and $\mathrm{b}$ ) but instead considerably increased responding for saccharin $\left(\mathrm{F}_{(1,6)}=37.12, p<0.01\right)$, compared with when rats had only access to saccharin (Figure $5 \mathrm{c}$ and $\mathrm{d}$ and Supplementary Results).

\section{Experiment 6: Effects of Prechoice Drug Administration on Drug Choices in a Discrete Choice Setting}

The above findings show that when rats are shifted to a setting where choosing under the drug influence is possible, the resulting patterns of drug choices mainly depend on the nature of this influence on sweet reward. To directly demonstrate this drug-specific influence, while keeping all else equal, we artificially manipulated it by passively administering cocaine or heroin before each choice trial. As expected, passive prechoice administration of cocaine in rats S/C dose-dependently increased cocaine choices compared with baseline (Figure 6a) $\left(\mathrm{F}_{(2,28)}=52.98, p<0.01\right)$. At the highest prechoice dose tested, rats shifted their preference away from saccharin to cocaine. In contrast, however, passive prechoice administration of heroin in rats $\mathrm{S} / \mathrm{H}$ did not increase but instead dose-dependently decreased heroin choices, thereby further increasing the initial preference for saccharin (Figure 6b) $\left(\mathrm{F}_{(2,32)}=5.86\right.$, $p<0.01)$. Note that regardless of the prechoice dose tested, rats completed most choice trials (rats S/C: $99.7 \pm 0.3$ and $88.8 \pm 2.1 \%$; rats $\mathrm{S} / \mathrm{H}: 99.5 \pm 0.3$ and $98.8 \pm 0.8 \%$ ). When prechoice drug administration was interrupted, percent of 

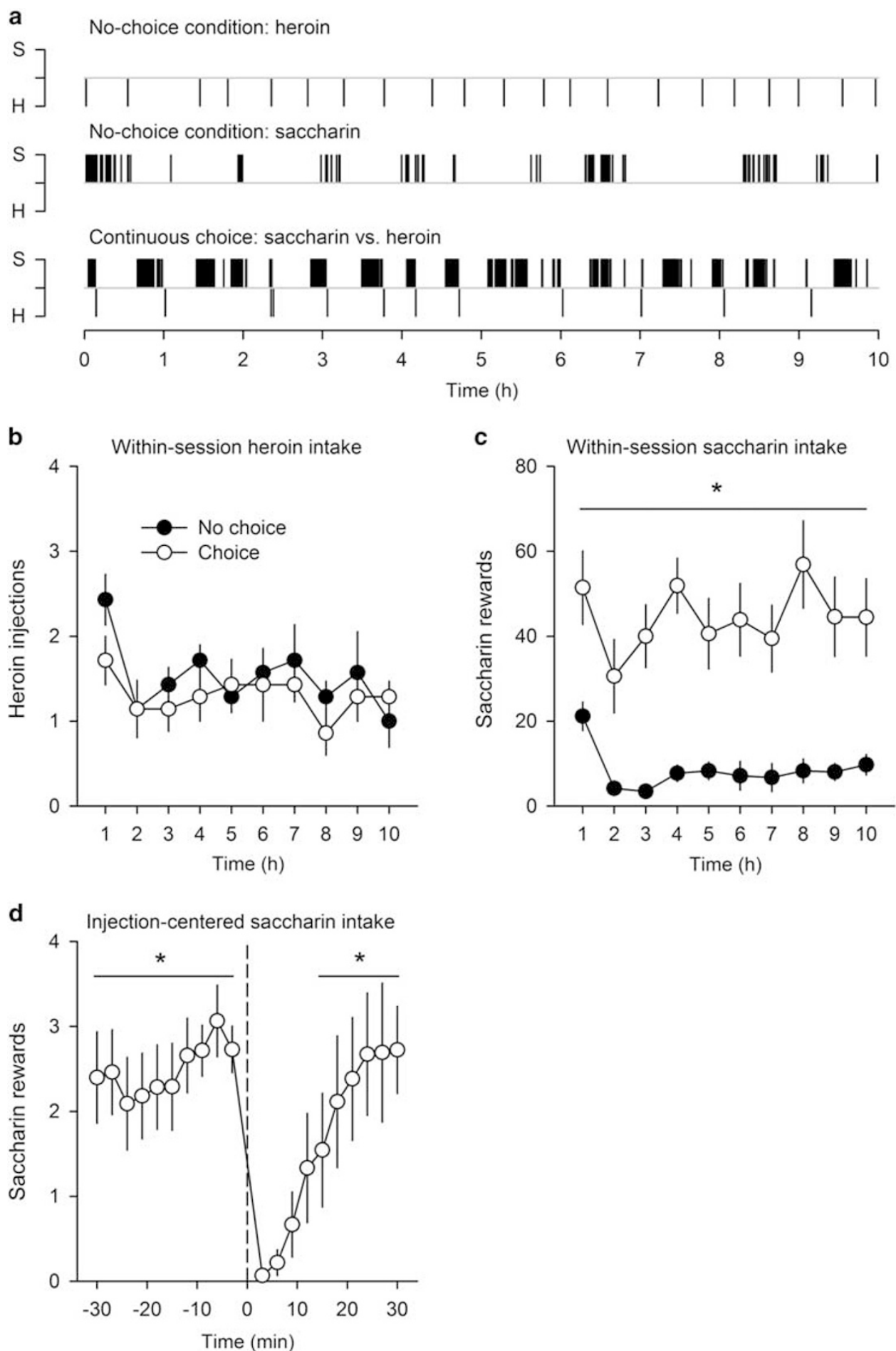

Figure 5 Choice between saccharin and a high dose of heroin in a continuous choice setting. (a) Within-session distribution of saccharin (0.2\%) and heroin (0.08 $\mathrm{mg}$ per injection) when only one reward or both rewards were available during $10 \mathrm{~h}$ to the same representative individual rat. (b) Mean ( \pm SEM) withinsession time course of heroin $(0.08 \mathrm{mg})$ rewards alone (no choice) or during continuous access to $0.2 \%$ saccharin $(c h o i c e)(n=7)$. (c) Mean $( \pm$ SEM) withinsession time course of saccharin rewards alone or during continuous access to heroin $(0.08 \mathrm{mg})(n=7)$. *Different from the 'no choice' condition ( $p<0.01$, main effect, ANOVA with repeated measures). (d) Mean ( \pm SEM) saccharin rewards centered around all heroin injections. Time 0 indicates the onset of heroin injections. *Different from time 0 ( $p<0.05$, Tukey's post hoc). 
a

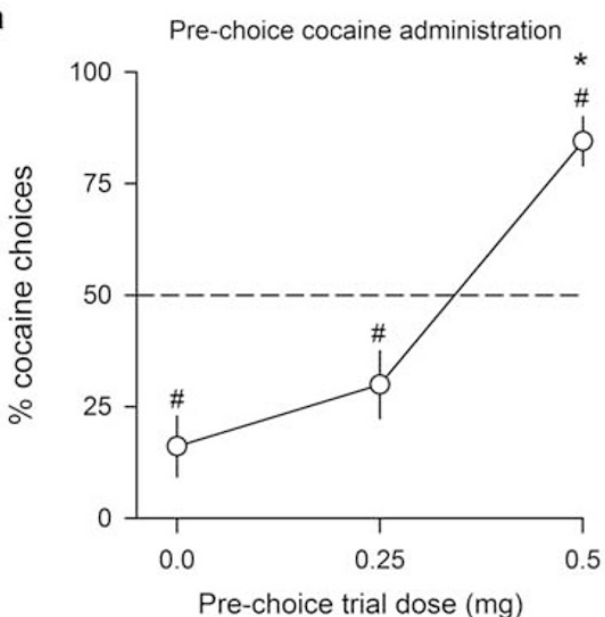

c

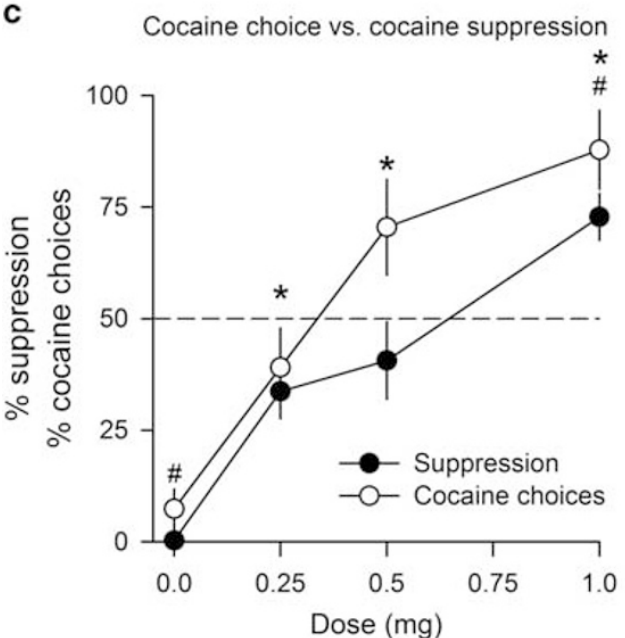

b

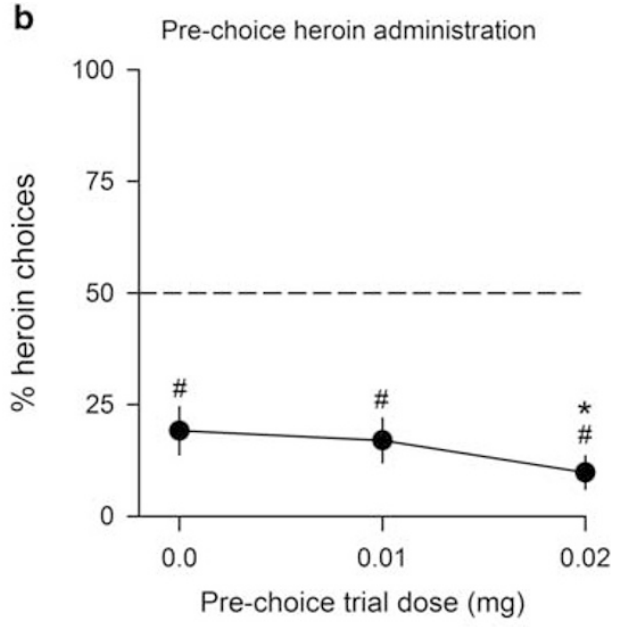

d Correlation analysis

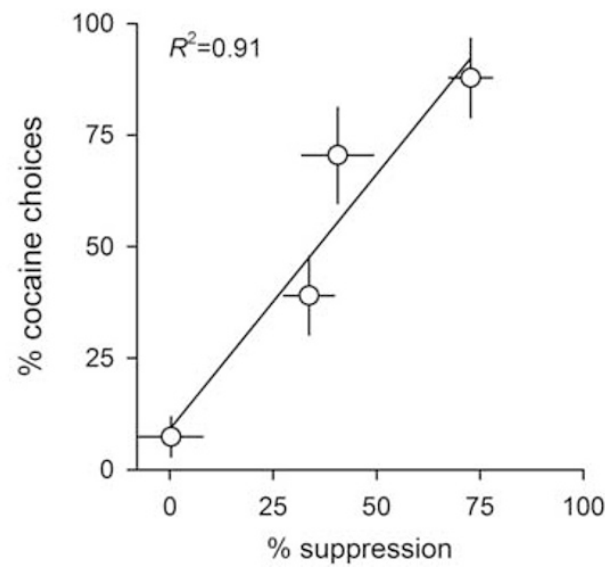

Figure 6 Manipulation of the direct acute effects of cocaine or heroin before choice trials in a discrete choice setting. (a) Mean ( \pm SEM) percent cocaine choices as a function of the prechoice dose of cocaine. (b) Mean ( \pm SEM) percent heroin choices as a function of the prechoice dose of heroin. (c) Doseeffect induction of cocaine choices by prechoice cocaine versus its dose-effect suppression of saccharin self-administration. (d) Dose-effect correlation between cocaine-induced suppression of saccharin self-administration and prechoice cocaine-induced increased cocaine choices. In all panels: *different from dose 0 ( $p<0.0$ I, Tukey's post hoc); ${ }^{\#}$ different from the indifference level of $50 \%$ ( $p<0.01$; $t$-test).

drug choices immediately returned to baseline levels in one session (rats S/C: $16.1 \pm 6.8 \%$ versus $17.5 \pm 7.2$; rats $\mathrm{S} / \mathrm{H}$ : $19.1 \pm 6.3$ versus $25.0 \pm 7.1 \%)$.

\section{Experiment 7: Correlation between Cocaine-Induced Suppression of Sweet Reward and Cocaine-Induced Cocaine Choices in a Discrete Choice Setting}

To further assess the origin of the effect of prechoice cocaine administration on cocaine choices, we studied its relationship with cocaine-induced suppression of saccharin selfadministration. We first measured in the same rats the dose-effect functions for cocaine-induced suppression of saccharin self-administration and then correlated it with that for prechoice cocaine-induced increase in cocaine choices. As expected, cocaine dose-dependently suppressed saccharin self-administration (Figure $6 \mathrm{c})\left(\mathrm{F}_{(3,30)}=28.87, p<0.01\right)$ and dose-dependently shifted choices to cocaine (Figure 6c) $\left(F_{(3,30)}=29.80, p<0.01\right)$. There was a strong correlation between the effectiveness of cocaine to suppress saccharin self-administration and its effectiveness to increase cocaine choices when administered before choice trials (Figure 6d) $\left(R^{2}=0.91, p<0.05\right)$.

\section{Follow-Up of Experiment 1: Stability and Reversibility of Cocaine and Heroin Choices}

The patterns of nonexclusive versus exclusive drug choices of rats $\mathrm{S} / \mathrm{H}$ and rats $\mathrm{S} / \mathrm{C}$, respectively, were observed on the very first session after the shift from the discrete to the continuous choice setting. A follow-up study revealed that these patterns remain largely unchanged with repeated sessions (11 in total; Supplementary Figure S3 and Supplementary Results). In particular, rats S/C continued to rapidly transition within each session to exclusive cocaine choices at the expense of sweet reward. Despite this stability, however, when all rats were retested in the discrete choice setting with a 10-min interval for 5 additional sessions, they re-expressed a preference for saccharin from the first session onwards (percent drug choices during first versus fifth session, rats S/C: $28.1 \pm 7.4$ versus $17.2 \pm 6.2 \%$; rats $\mathrm{S} / \mathrm{H}$ : $22.8 \pm 6.0$ versus $18.4 \pm 6.9 \%)$. 
Experiment 8: Assessment of Ability to Associate Cocaine Self-Administration with Suppression of Sweet Reward

This last experiment was designed to better understand why rats S/C kept transitioning to exclusive cocaine choices during repeated continuous choice testing despite its negative influence on sweet reward-their preferred reward. In theory, a forward-looking, reward-maximizing animal should have learned with repeated testing to refrain from doing so, at least partly. Our negative findings may thus suggest that rats would be incapable of such learning. To test this hypothesis, a separate group of rats $(n=14)$ was trained in a procedure optimally designed to promote this form of learning. Rats were trained to self-administer saccharin during two successive blocks, one block before (block 1) and one block immediately after cocaine self-administration (block 2). Comparing saccharin self-administration between these two blocks should allow a forward-looking animal to anticipate that initiating cocaine self-administration $(0.25 \mathrm{mg}$ per injection) will suppress their preferred reward and thus to refrain from doing it. This did not happen in rats, however. Although cocaine selfadministration suppressed saccharin self-administration during block 2 compared with block 1 (Figure $7 \mathrm{a})\left(\mathrm{F}_{(1,13)}=152.94\right.$, $p<0.01$; no interaction), rats did not reduce their intake of cocaine even after 14 daily sessions (Figure $7 \mathrm{~b}$ ).

\section{DISCUSSION}

The present study demonstrates that the choice setting controls drug choices in rats by regulating the drug influence on other options-water sweetened with saccharin here-at the time of choice. In a setting where choosing under the drug influence is not possible, most rats choose sweet reward over either cocaine or heroin, indicating that rats normally attribute more reward and/or incentive value to saccharin than to either drug. In contrast, when rats are shifted to a setting where choosing under the influence is possible, they rapidly develop after the first drug choices a pattern of nonexclusive or exclusive drug choices depending on whether the drug enhances or suppresses sweet reward, respectively. Thus, when rats are under the orexigenic effects of heroin, they take more saccharin in alternation with heroin - an effect particularly obvious at the high dose of heroin. In contrast, when rats are under the anorexic effects of cocaine, they stop taking saccharin and shift to cocaine almost exclusively. These setting- and drug-specific changes in drug choices are rapid and fully reversible, and can be artificially induced by passively administering cocaine or heroin before choice. The opposite influence of cocaine and heroin on drug choices shows that the underlying mechanism is not a direct modulation of drug motivation (which is increased by both cocaine and heroin) but rather a direct modulation of sweet motivation.

One of the most striking results of the present study is the opposite and reversible pattern of cocaine choices seen when the same rats are shifted between different choice settings. Specifically, when rats are shifted from a setting where choosing under the influence of cocaine is prevented to a setting where this influence is possible, their choices shift from sweet reward to cocaine almost exclusively after only few initial cocaine choices. Inversely, when they experience
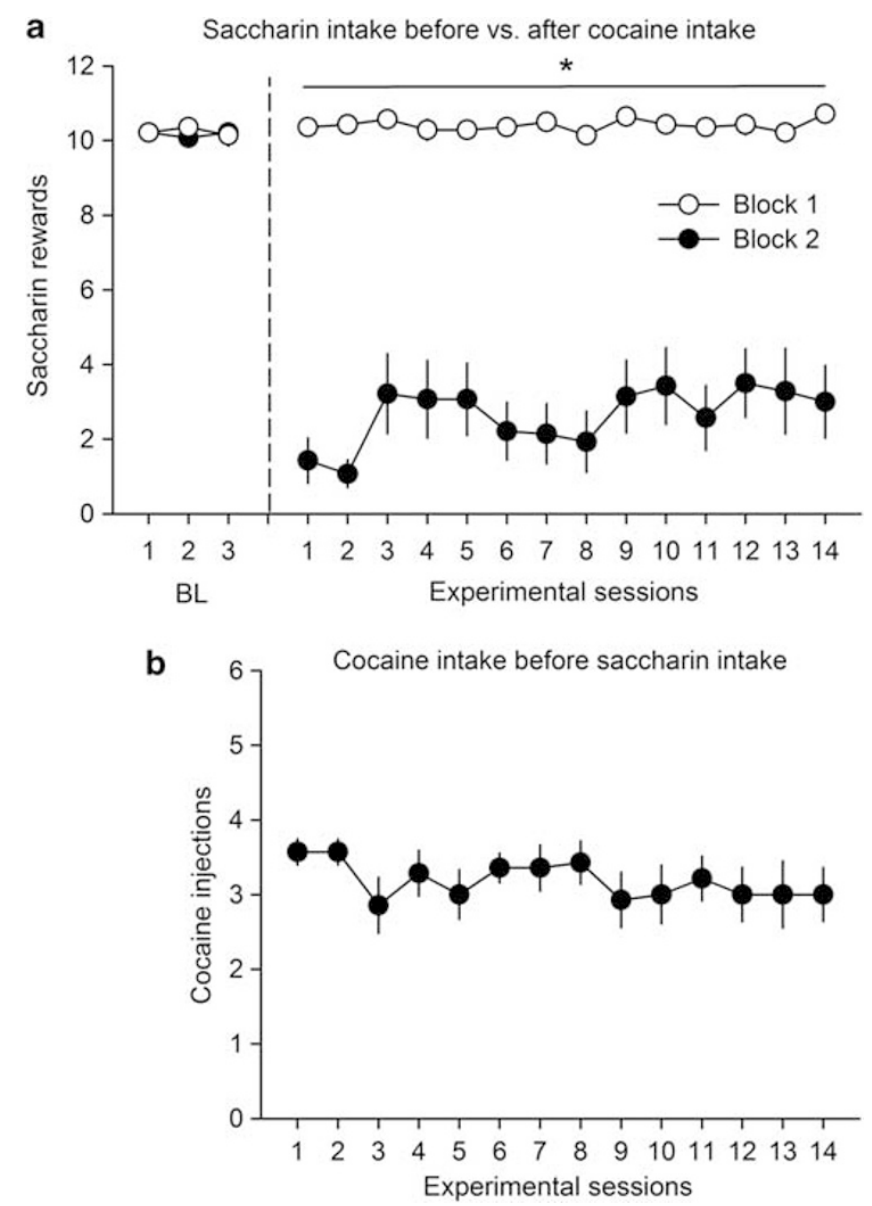

Figure 7 Cocaine self-administration before access to saccharin. (a) Mean ( \pm SEM) saccharin $(0.2 \%$, last 3 baseline sessions followed by 14 testing sessions) self-administration during block I and block 2 . Note that during baseline (BL) sessions, the number of saccharin rewards was identical during blocks I and 2. *Different from block 2 ( $p<0.01$, main effect, ANOVA with repeated measures). (b) Mean ( \pm SEM) cocaine injections before access to saccharin during block 2. Cocaine self-administration was limited to a maximum of 4 injections.

the opposite shift in setting, they immediately return to their preference for sweet reward. Apparently, the critical setting parameter underlying this effect is the length of the interchoice interval. Other important setting parameters (eg, the discreteness, number, or mutually exclusiveness of choice trials) do not seem to be involved. Indeed, all else being equal, merely shortening the interchoice interval from 10 to $1 \mathrm{~min}$ was sufficient to make rats shift their choice from saccharin to cocaine within one single 30-trial choice session. This setting-specific control of cocaine choices in the same rats and at the same dose of cocaine (ie, $0.25 \mathrm{mg}$ per injection) confirms previous research (Kerstetter et al, 2012) and helps to resolve current discrepancies across cocaine choice studies in rats, as explained in the Introduction (Lenoir et al, 2007; Thomsen et al, 2013).

The transition to exclusive cocaine choices was also observed in hungry rats offered a continuous choice between sucrose and cocaine during several hours, despite the opportunity cost in terms of missed calories (see below). Thus, once rats make the first cocaine choices in a setting where choosing under the influence of cocaine is possible, it 
is as if they enter a locked-in pattern of exclusive drug use from which they seem unable to escape. In such a setting, once rats make a cocaine choice, the resulting anorexic effects automatically spill over to the next choice to bias it toward more cocaine and on and on. Importantly, rats seem not only unable to escape from this locked-in pattern once in, but are also apparently unable to learn with repeated experience to avoid it by refraining from making drug choices. In fact, even under optimal learning conditions and while they are not yet under the influence of cocaine, rats nevertheless keep continuing over repeated sessions to initiate cocaine use before access to saccharin, despite this leading systematically to a suppression of sweet reward-their normally preferred reward. The mechanism of this inability is not clear at present. It may reflect rats' inherent limitation to foresee the negative influence that taking cocaine now will have few min later on sweet reward. Unlike humans, rats are relatively 'stuck in time' (Roberts, 2002; Suddendorf and Corballis, 2007). They can foresee certain future events, as when they pursue immediate goals (Corballis, 2013; Dickinson and Balleine, 1994; Johnson and Redish, 2007), but their time horizon is likely too narrow to encompass the delayed direct influence of a current drug choice on future choices. In addition, though rats can clearly perceive their current internal states, like hunger or even a drug state (Colpaert et al, 1978; Overton, 1991), they seem unable to represent their future internal states and thus ignore them when making a current choice (Roberts, 2002; Suddendorf and Corballis, 2007).

Regardless of the exact mechanism of rats' inability to avoid developing a pattern of exclusive cocaine choices, however, it makes them highly vulnerable to harm themselves in certain choice settings, notably when the excluded options are socially and/or biologically important. This prediction has been previously observed in rats given unlimited access to cocaine self-administration during several weeks in their home cage environments where they also had free access to food and water (Bozarth and Wise, 1985). Most of them self-administered cocaine to the exclusion of food and water, and to the point of death. The only way to protect rats from developing such a selfdestructive pattern of exclusive cocaine choices seems to be through an outside intervention. As shown here, this intervention could be aimed at restructuring the choice setting to prevent choosing under the influence of cocaine and/or to supply a different drug that does not suppress food and water intake, like heroin. The latter prediction has been observed in rats given unlimited access to heroin selfadministration during several weeks in their home cage environments. As expected, most of these rats did not develop a self-destructive pattern of exclusive heroin choices and instead took heroin in alternation with water and food (Bozarth and Wise, 1985; Chen et al, 2006).

Thus, when rats are shifted to a setting where choosing under the drug influence is possible, they develop a pattern of nonexclusive or exclusive drug choices depending on whether the drug enhances or suppresses sweet reward, respectively. In the present study, a pattern of exclusive drug choices was only observed with cocaine but not with heroin. This difference between cocaine and heroin is unlikely to be absolute, however, but rather relative to the nature of the competing option used in the present study. In theory, in a setting where choosing under the influence is possible, a given drug should induce a nonexclusive or an exclusive pattern of drug choices depending on how it directly influences the specific nondrug option available. For instance, if rats were offered a continuous choice between cocaine and a nondrug option whose value is not suppressed but instead enhanced by cocaine, then one should expect that they will develop a nonexclusive pattern of cocaine choices, like that reported here between heroin and saccharin. This prediction has been previously observed in an old study on amphetamine self-administration (Wise et al, 1977)-a stimulant drug that, like cocaine, powerfully suppresses food intake (Cooper et al, 1989). In this study, rats were free to allocate their choices between amphetamine self-administration and a different behavior that is potentiated by the direct acute effects of amphetamine, that is, intracranial selfstimulation (Esposito et al, 1980). As expected, after initiation of amphetamine self-administration, rats not only continued to respond for intracranial stimulation in alternation with amphetamine self-administration but even responded more for it (Wise et al, 1977). This pattern resembles that reported here between the high dose of heroin and saccharin. Inversely, if rats were offered a choice between heroin and a nondrug option that is not enhanced but suppressed by heroin, then one should expect that they will develop a pattern of exclusive heroin choices. Thus, what ultimately counts in determining whether rats will develop a nonexclusive or exclusive pattern of drug self-administration in a setting where choosing under the drug influence is possible is the nature of the interaction between the drug and the nondrug option.

The above considerations also help us to realize that the harmfulness of a pattern of drug choices does not only depend on the primary toxic effects of the self-administered drug (eg, its damaging impact on certain organs), but also secondarily on the benefits/costs associated with the excluded or enhanced competing behavioral options. As discussed above, a pattern of exclusive drug choices can become fatal in the long run in rats if the excluded options are biologically essential for survival. However, the same pattern of exclusive drug choices should not induce this secondary source of harmfulness if the excluded options are not essential or important. In theory, this pattern could even reduce harms if the excluded options were themselves harmful. Similarly, a pattern of nonexclusive drug choices that enhances other competing options should not induce any additional source of harmfulness if the enhanced competing options are themselves neutral or beneficial. In contrast, if the enhanced options are themselves harmful, then even a pattern of nonexclusive drug choices could eventually become secondarily harmful in addition to the primary toxic effects of the self-administered drug. For instance, in the present study, the avid consumption of saccharin (ie, approximately one-third of rats' body weight) observed between the high doses of heroin could eventually harm rats' health if repeated over an extended period of time. Thus, a pattern of nonexclusive drug choices is not necessarily less secondarily harmful than a pattern of exclusive drug choices.

In conclusion, the present study confirms the importance of the setting in determining patterns of drug choices in both rats and humans (Alexander and Hadaway, 1982; Badiani, 2013; Falk, 1983; Faupel, 1987; Zinberg, 1984). It also demonstrates that some settings are more conducive to harmful patterns of 
drug choices than other settings and this despite the availability of other highly rewarding behaviors. We found that the setting controls the pattern of drug choices in rats primarily by regulating the drug influence on other competing options at the time of choice. Importantly, rats behave as if they were oblivious to this influence. This behavior could explain why rats are vulnerable to harm themselves, even to the point of death, in settings where their choices are made under the drug influence, notably if the drug influence excludes other important available activities or, conversely, enhances harmful ones. An important goal for future research will be to determine whether and to what extent the setting involves a similar drug influence mechanism to control drug choices in other animal species, including humans. Although this mechanism has not been explicitly tested in nonhuman primates, it is likely because, like rats, these animals also selfadminister stimulant drugs with anorexic properties to the exclusion of food and to the point of death (Johanson et al, 1976). In humans, there is some evidence that the direct acute effects of cocaine at the moment of choice can increase choice of cocaine over money in people with cocaine addiction (Donny et al, 2004; Vosburg et al, 2010). It is unknown, however, whether the latter effect involves a direct influence of the drug on the value of or motivation for the nondrug option available, like it does in rats. Finally, the importance attributed here to both the setting and the nonhedonic effects of different drugs is consistent with previous research by Badiani and colleagues (Badiani, 2013; Badiani et al, 2011). According to these authors, the setting will not only control the presence or absence of the nonhedonic effects of the drug at the time of choice, as emphasized here, but will also modulate how these effects are affectively evaluated. For instance, the sedative effects of heroin are hypothesized to be evaluated more negatively in an unfamiliar setting than at home which would explain why heroin is less rewarding outside the home setting (Caprioli et al, 2008). More generally, this setting-dependent evaluation would explain why most individuals prefer using certain drugs in a given setting (eg, heroin is preferred over cocaine at home) (Caprioli et al, 2009) and why they prefer certain settings to use a given drug (eg, home is preferred for using heroin) (Caprioli et al, 2007, 2008). Whether this settingdependent evaluation can be generalized to all nonhedonic effects of cocaine and heroin, in particular to their orexigenic or anorexigenic effects that are the focus of this study, is not clear at present and deserve additional research (Paolone et al, 2003). Nevertheless, when integrated, the present research and that of Badiani and colleagues (Badiani, 2013; Badiani et al, 2011) define a comprehensive framework for better understanding how the setting can control patterns of drug choices in a drug-specific manner.

\section{FUNDING AND DISCLOSURE}

The authors declare no conflict of interest.

\section{ACKNOWLEDGMENTS}

We thank Ourida Gaucher and Jean-Philippe Fougères for administrative assistance. We also thank Drs Karine Guillem, Magalie Lenoir, and Hanna Pickard for their helpful comments on a previous version of the manuscript. Finally, we thank the reviewers for their constructive criticisms. This research was supported by funding from the Centre National de la Recherche Scientifique (CNRS), the Agence Nationale de la Recherche (ANR- 2010-BLAN-1404-01, ANR-12SAMA-003 01), the Universite de Bordeaux, the Conseil Regional d'Aquitaine (CRA11004375/11004699), the Ministère de la Recherche et de l'Enseignement Supérieur, and the Labex BRAIN.

\section{REFERENCES}

Ahmed SH (2005). Imbalance between drug and non-drug reward availability: a major risk factor for addiction. Eur J Pharmacol 526: 9-20.

Ahmed SH (2010). Validation crisis in animal models of drug addiction: beyond non-disordered drug use toward drug addiction. Neurosci Biobehav Rev 35: 172-184.

Ahmed SH (2012). The science of making drug-addicted animals. Neuroscience 211: 107-125.

Ahmed SH, Cador M (2006). Dissociation of psychomotor sensitization from compulsive cocaine consumption. Neuropsychopharmacology 31: 563-571.

Ahmed SH, Lenoir M, Guillem K (2013). Neurobiology of addiction versus drug use driven by lack of choice. Curr Opin Neurobiol 23: 581-587.

Alexander BK, Hadaway PF (1982). Opiate addiction: the case for an adaptive orientation. Psychol Bull 92: 367-381.

Badiani A (2013). Substance-specific environmental influences on drug use and drug preference in animals and humans. Curr Opin Neurobiol 23: 588-596.

Badiani A, Belin D, Epstein D, Calu D, Shaham Y (2011). Opiate versus psychostimulant addiction: the differences do matter. Nat Rev Neurosci 12: 685-700.

Balopole DC, Hansult CD, Dorph D (1979). Effect of cocaine on food intake in rats. Psychopharmacology (Berl) 64: 121-122.

Bozarth MA, Wise RA (1985). Toxicity associated with long-term intravenous heroin and cocaine self-administration in the rat. JAMA 254: 81-83.

Cantin L, Lenoir M, Augier E, Vanhille N, Dubreucq S, Serre F et al (2010). Cocaine is low on the value ladder of rats: possible evidence for resilience to addiction. PLoS One 5: e11592.

Caprioli D, Celentano M, Dubla A, Lucantonio F, Nencini P, Badiani A (2009). Ambience and drug choice: cocaine- and heroin-taking as a function of environmental context in humans and rats. Biol Psychiatry 65: 893-899.

Caprioli D, Celentano M, Paolone G, Lucantonio F, Bari A, Nencini $P$ et al (2008). Opposite environmental regulation of heroin and amphetamine self-administration in the rat. Psychopharmacology (Berl) 198: 395-404.

Caprioli D, Paolone G, Celentano M, Testa A, Nencini P, Badiani A (2007). Environmental modulation of cocaine self-administration in the rat. Psychopharmacology (Berl) 192: 397-406.

Caprioli D, Venniro M, Zeric T, Li X, Adhikary S, Madangopal R et al (2015a). Effect of the novel positive allosteric modulator of metabotropic glutamate receptor 2 AZD8529 on incubation of methamphetamine craving after prolonged voluntary abstinence in a rat model. Biol Psychiatry.

Caprioli D, Zeric T, Thorndike EB, Venniro M (2015b). Persistent palatable food preference in rats with a history of limited and extended access to methamphetamine self-administration. Addict Biol.

Carroll ME, Lac ST (1993). Autoshaping i.v. cocaine selfadministration in rats: effects of nondrug alternative reinforcers on acquisition. Psychopharmacology (Berl) 110: 5-12.

Carroll ME, Lac ST, Nygaard SL (1989). A concurrently available nondrug reinforcer prevents the acquisition or decreases the 
maintenance of cocaine-reinforced behavior. Psychopharmacology (Berl) 97: 23-29.

Chen SA, O'Dell LE, Hoefer ME, Greenwell TN, Zorrilla EP, Koob GF (2006). Unlimited access to heroin self-administration: independent motivational markers of opiate dependence. Neuropsychopharmacology 31: 2692-2707.

Colpaert FC, Niemegeers CJ, Janssen PA (1978). Discriminative stimulus properties of cocaine and d-amphetamine, and antagonism by haloperidol: a comparative study. Neuropharmacology 17: 937-942.

Cooper SJ (1982). Palatability-induced drinking after administration of morphine, naltrexone and diazepam in the non-deprived rat. Subst Alcohol Actions Misuse 3: 259-266.

Cooper SJ, Rusk IN, Barber DJ (1989). Sucrose sham-feeding in the rat after administration of the selective dopamine D2 receptor agonist N-0437, d-amphetamine or cocaine. Pharmacol Biochem Behav 32: 447-452.

Cooper SJ, van der Hoek GA (1993). Cocaine: a microstructural analysis of its effects on feeding and associated behaviour in the rat. Brain Res 608: 45-51.

Corballis MC (2013). Mental time travel: a case for evolutionary continuity. Trends Cogn Sci 17: 5-6.

de Wit H, Stewart J (1981). Reinstatement of cocaine-reinforced responding in the rat. Psychopharmacology (Berl) 75: 134-143.

de Wit H, Stewart J (1983). Drug reinstatement of heroin-reinforced responding in the rat. Psychopharmacology (Berl) 79: 29-31.

Dickinson A, Balleine BW (1994). Motivational control of goaldirected action. Anim Learn Behav 22: 1-18.

Donny EC, Bigelow GE, Walsh SL (2004). Assessing the initiation of cocaine self-administration in humans during abstinence: effects of dose, alternative reinforcement, and priming. Psychopharmacology (Berl) 172: 316-323.

Esposito RU, Perry W, Kornetsky C (1980). Effects of d-amphetamine and naloxone on brain stimulation reward. Psychopharmacology (Berl) 69: 187-191.

Falk JL (1983). Drug dependence: myth or motive? Pharmacol Biochem Behav 19: 385-391.

Faupel CE (1987). Drug availability, life structure, and situational ethics of heroin addicts. Urban Life 15: 395-419.

Hyman SE, Malenka RC (2001). Addiction and the brain: the neurobiology of compulsion and its persistence. Nat Rev Neurosci 2: 695-703.

Johanson CE, Balster RL, Bonese K (1976). Self-administration of psychomotor stimulant drugs: the effects of unlimited access. Pharmacol Biochem Behav 4: 45-51.

Johnson A, Redish AD (2007). Neural ensembles in CA3 transiently encode paths forward of the animal at a decision point. J Neurosci 27: 12176-12189.

Kerstetter KA, Ballis MA, Duffin-Lutgen S, Carr AE, Behrens AM, Kippin TE (2012). Sex differences in selecting between food and cocaine reinforcement are mediated by estrogen. Neuropsychopharmacology 37: 2605-2614.

Lenoir M, Ahmed SH (2007). Heroin-induced reinstatement is specific to compulsive heroin use and dissociable from heroin reward and sensitization. Neuropsychopharmacology 32: 616-624.

Lenoir M, Cantin L, Vanhille N, Serre F, Ahmed SH (2013). Extended heroin access increases heroin choices over a potent nondrug alternative. Neuropsychopharmacology 38: 1209-1220.

Lenoir M, Serre F, Cantin L, Ahmed SH (2007). Intense sweetness surpasses cocaine reward. PLoS One 2: e698.

Le Sage MG (2009). Toward a nonhuman model of contingency management: effects of reinforcing abstinence from nicotine selfadministration in rats with an alternative nondrug reinforcer. Psychopharmacology (Berl) 203: 13-22.
Liu C, Grigson PS (2005). Brief access to sweets protect against relapse to cocaine-seeking. Brain Res 1049: 128-131.

Madsen HB, Ahmed SH (2015). Drug versus sweet reward: greater attraction to and preference for sweet versus drug cues. Addict Biol 20: 433-444.

Overton DA (1991). A historical perspective on drug discrimination. NIDA Res Monogr 116: 5-24.

Paolone G, Burdino R, Badiani A (2003). Dissociation in the modulatory effects of environmental novelty on the locomotor, analgesic, and eating response to acute and repeated morphine in the rat. Psychopharmacology (Berl) 166: 146-155.

Parker LA, Maier S, Rennie M, Crebolder J (1992). Morphine- and naltrexone-induced modification of palatability: analysis by the taste reactivity test. Behav Neurosci 106: 999-1010.

Perry AN, Westenbroek C, Becker JB (2013). The development of a preference for cocaine over food identifies individual rats with addiction-like behaviors. PLoS One 8: e79465.

Rideout HJ, Parker LA (1996). Morphine enhancement of sucrose palatability: analysis by the taste reactivity test. Pharmacol Biochem Behav 53: 731-734.

Roberts WA (2002). Are animals stuck in time? Psychol Bull 128: 473-489.

Setlow B, Mendez IA, Mitchell MR, Simon NW (2009). Effects of chronic administration of drugs of abuse on impulsive choice (delay discounting) in animal models. Behav Pharmacol 20: 380-389.

Shaham Y, Shalev U, Lu L, De Wit H, Stewart J (2003). The reinstatement model of drug relapse: history, methodology and major findings. Psychopharmacology (Berl) 168: 3-20.

Spronk DB, van Wel JH, Ramaekers JG, Verkes RJ (2013). Characterizing the cognitive effects of cocaine: a comprehensive review. Neurosci Biobehav Rev 37: 1838-1859.

Suddendorf T, Corballis MC (2007). The evolution of foresight: what is mental time travel, and is it unique to humans? Behav Brain Sci 30: 299-313; discussion 313-251.

Thomsen M, Barrett AC, Negus SS, Caine SB (2013). Cocaine versus food choice procedure in rats: environmental manipulations and effects of amphetamine. J Exp Anal Behav 99: 211-233.

Thomsen M, Fink-Jensen A, Woldbye DP, Wortwein G, Sager TN, Holm R et al (2008). Effects of acute and chronic aripiprazole treatment on choice between cocaine self-administration and food under a concurrent schedule of reinforcement in rats. Psychopharmacology (Berl) 201: 43-53.

Tunstall BJ, Kearns DN (2013). Reinstatement in a cocaine versus food choice situation: reversal of preference between drug and non-drug rewards. Addict Biol 19: 838-848.

Tunstall BJ, Riley AL, Kearns DN (2014). Drug specificity in drug versus food choice in male rats. Exp Clin Psychopharmacol 22: 364-372.

Vosburg SK, Haney M, Rubin E, Foltin RW (2010). Using a novel alternative to drug choice in a human laboratory model of a cocaine binge: a game of chance. Drug Alcohol Depend 110: 144-150.

Wise RA, Yokel RA, Hansson PA, Gerber GJ (1977). Concurrent intracranial self-stimulation and amphetamine self-administration in rats. Pharmacol Biochem Behav 7: 459-461.

Wolgin DL, Hertz JM (1995). Effects of acute and chronic cocaine on milk intake, body weight, and activity in bottle- and cannulafed rats. Behav Pharmacol 6: 746-753.

Woolverton WL, Kandel D, Schuster CR (1978). Tolerance and cross-tolerance to cocaine and d-amphetamine. J Pharmacol Exp Ther 205: 525-535.

Zernig G, Kummer KK, Prast JM (2013). Dyadic social interaction as an alternative reward to cocaine. Front Psychiatry 4: 100.

Zinberg NE (1984). Drug, Set, and Setting: The Basis of Controlled Intoxicant Use. Yale University Press: New Haven.

Supplementary Information accompanies the paper on the Neuropsychopharmacology website (http://www.nature.com/npp) 